\begin{tabular}{|l|l|}
\hline RECIBIDO / RECEIVED & 18 de marzo de 2018 \\
\hline ACEPTADO / ACEPTED & 14 de noviembre de 2018 \\
\hline PÁGINAS / PAGES & De la 41 a la 54 \\
\hline ISSN / ISSN & $2386-2912$ \\
\hline
\end{tabular}

\title{
¿Fue escotista la Universidad de Alcalá de Henares?* A propósito de una afirmación de Marcel Bataillon
}

\section{Was Scotist the University of Alcalá de Henares? \\ On a Marcel Bataillon's statement}

El artículo estudia la fundación de la Universidad de Alcalá de Henares en el contexto de la reforma político-eclesiástica promovida por los Reyes Católicos y por el propio Cardenal Cisneros, su fundador. Posteriormente se presentan dos disputas suscitadas por Marcel Bataillon en relación con la Universidad de Alcalá: la primera, sobre el carácter eclesiástico o humanístico de la misma; la segunda, sobre la hipotética pretensión cisneriana de introducir por su medio el escotismo en España.

\section{\#Reyes católicos \#Cisneros \#Bataillon \#Beltrán de Heredia \#García Villoslada}

The article studies the foundation of the University of Alcalá de Henares in the context of the political-ecclesiastical reform promoted by the Reyes Católicos and by Cardinal Cisneros himself, its founder. The article presents and evaluates later two questions raised by Marcel Bataillon in relation to the University of Alcalá: the first one, the character purely ecclesiastical, not humanistic, of said University; the second one, the Cisneros's hypothetical pretension to introduce through this University the Scotism in Spain.

\section{\#Reyes católicos \#Cisneros \#Bataillon \#Beltrán de Heredia \#García Villoslada}

* Este artículo se enmarca en el Proyecto Nacional Competitivo I+D (Convocatoria de Proyectos Excelencia 2017) "Sociedad, política y economía: Proyecciones de la Escolástica española en el pensamiento británico y anglosajón" (FFI2017-84435-P), financiado por el Ministerio de Economía, Industria y Competitividad (MINECO), del que el autor es el primer investigador principal. 
La fundación de la Universidad de Alcalá y la reforma universitaria en España impulsada por el cardenal Cisneros no se entienden sino dentro del contexto de reforma política y eclesiástica promovida por Isabel y Fernando en la España del Renacimiento. Este es el contexto general de este artículo, estudiado en los tres primeros epígrafes. Pero la cuestión particular aquí estudiada y el objeto fundamental de este trabajo es la valoración de la afirmación de Marcel Bataillon en su Erasmo y España sobre el propósito de Cisneros de hacer de la Universidad de Alcalá una Academia escotista por cuyo medio se pretendía introducir en España la doctrina del Doctor Sutil.

Como el lector comprobará la disposición del artículo consiste en un acercamiento progresivo a esta última cuestión a lo largo de los cuatro epígrafes que lo integran. En efecto, después de abordar (1) la cuestión de la reforma político-eclesiástica de los Reyes Católicos, realizada en parte por medio del propio cardenal Cisneros, (2) cuyos rasgos biográficos más sobresalientes son de obligada exposición, vamos a ver hasta qué punto (3) la fundación de la Universidad de Alcalá se inscribe de lleno dentro del plan de reforma eclesiástica realizado por el Cardenal de España, a la vez que recoge inequívocamente los fermentos del humanismo. Una vez llegados aquí, finalmente, será el momento de (4) examinar y valorar la tesis de Bataillon según la cual la creación de la Universidad de Alcalá entrañaba la pretensión cisneriana de difundir el escotismo en España.

El lector advertirá igualmente en los dos primeros epígrafes del artículo una poco frecuente abundancia de citas que reenvían al historiador de la Iglesia García Villoslada. Ello se debe a los dos siguientes motivos: El primero es que más allá de su competencia científica, que es la Historia del pensamiento moderno, quien escribe estas líneas admite francamente su impericia en el campo inabarcable de la Historia de la Iglesia, del que, sin embargo, reconoce a García Villoslada como un historiador sobresaliente. La segunda es que, los escasos conocimientos de Historia de la Iglesia del que firma este artículo se obtuvieron hace ya muchos años precisamente de la lectura de las páginas, rigurosas a la vez que amenas y de un estilo límpido, escritas por el referido historiador jesuita, al que de algún modo este trabajo pretende rendir un modesto homenaje.

\section{Los planes de reforma política y eclesiástica de los Reyes Católicos}

El Papa Alejandro VI no otorgó en balde a los reyes Isabel y Fernando el apelativo de católicos en 1496. La concesión de este título respondió al hecho de que "supieron armonizar perfectamente los intereses nacionales y patrióticos con los de la santa Iglesia" (García Villoslada, 1987, p.606).

La situación de los reinos españoles en la segunda mitad del siglo XV en verdad era lastimosa y necesitada de reforma. El caso de Castilla en tiempos de Enrique IV (1454-1474) era el de un reino en una situación poco menos que anárquica. De nuevo con el mismo autor: 
En todas partes la inquietud social, las intrigas cortesanas, las banderías o facciones de familias de linaje enemigas, el bandolerismo de los campos, las represalias de los nobles contra las villas y el consiguiente desenfreno moral cundían de una manera alarmante. Existía además el peligroso fermento de falsos conversos, judíos y mahometanos. (García Villoslada, 1987, p. 602).

En esas circunstancias la tenaz voluntad de Isabel y Fernando de reconducir al orden la situación de sus respectivos reinos comenzó a dar frutos. En su Crónica de los Reyes Católicos nos dice Hernando del Pulgar:

En todos sus reinos poco antes había homes robadores y criminosos, que tenían diabólicas osadías, e sin temor de justicia cometían crímenes e feos delitos. E luego en pocos días, súpitamente, se imprimió en los corazones de todos tan gran miedo, que ninguno osaba cometer fuerza, ninguno decía mala palabra ni descortés. Todos se amansaron y pacificaron, todos estaban sometidos a la justicia e todos la tomaban para su defensa. Y el caballero y el escudero, que poco antes con soberbia sojuzgaban al labrador o al oficial, se sometían a la razón e no osaban enojar a ninguno por miedo de la justicia que el rey e la reina mandaban ejecutar. (Del Pulgar, 1780, p. 167).

Para someter a un pueblo que se había envilecido, se expidieron pragmáticas reales contra los juegos de azar, el lujo excesivo, los ladrones, vagabundos y viciosos. Las penas contra algunos delitos llegaron a ser severísimas (cf. García Villoslada, 1987, p.608).

En este ambiente no era de esperar en el clero de Castilla una moralidad muy por encima de la media. Bien al contrario, los documentos de la época presentan un triste cuadro tanto en el clero bajo como el alto. Los reyes, por ello, impulsaron una reforma eclesiástica cuyas razones no eran solo espirituales y religiosas, sino también político-administrativas. Ante los abusos, corrupciones y escándalos de los eclesiásticos urgieron la reforma al Papa y a los obispos, aun a riesgo de invadir un terreno que escapaba de su jurisdicción. En su obra Concilios nacionales inéditos daba buena cuenta el P. Fita de lo manifestado por los Reyes Católicos en el Concilio nacional de Sevilla (julio-agosto de 1478). En efecto, en la determinación XII decían los reyes:

Iten se pratique cómo, pues que á nuestro Señor ha placido de dar paze sosiego en estos nuestros Rey nose en los tres estados dellos, e por su infinita clemençiae nos confirmando lo que avemos comenzado, entendemos de reformar el estado seglar en quanto pudiéremos, reduciéndolo a la buena e antigua gobernación, que asymismo se provea cómo el estado eclesiástico se reforme asy en la libertad e ynmunidad eclesiástica e veneración de las iglesias como en las personas eclesiásticas e religiosas e honesto bevirdellas, e en todas las otras cosas al estado eclesiástico convenientes. (Fita, 1893, p. 219). 
Asimismo, ampliaron sus planes de reforma eclesiástica hasta hacerlos llegar no solo al clero, sino a también a los religiosos, mujeres y varones, fueran monjes o frailes. En tal sentido afirmaba Galíndez de Carvajal: "Asentado que fue lo de la justicia, entendieron en reformar las religiones de frailes y monjas, que estaban necesitadas de remedio" (Galíndez de Carvajal, 1970, p. 110).

Naturalmente la clave de la reforma de la Iglesia española estaba en la reforma de los obispos. Por ahí comenzaron Isabel y Fernando su obra restauradora:

En el proveer de las iglesias que vacaron en su tiempo -decía el cronista de la corte- hobo [lsabel] respeto tan recto, que, pospuesta toda afición, siempre suplicó al papa por hombres generosos e grandes letrados e de vida honesta, lo cual no se lee que con tanta diligencia hobiese guardado ningún rey de los pasados. (Del Pulgar, 1780, p. 37).

Los criterios que de ordinario guiaron la acción de los reyes para la elección de los obispos fueron estos: que se tratara de nacionales o "naturales destosreynos", que fuesen cumplidores de la obligación de residencia en sus diócesis, que no fuesen adversos u hostiles a la política real, que fuesen íntegros y de vida honesta y virtuosa; y finalmente que fueran cultos y letrados. De todos ellos, conocemos bien la importancia que los reyes daban particularmente a este último. En efecto, en las Capitulaciones matrimoniales para la gobernación del Reino convinieron Isabel y Fernando en:

que en las vacationes de los Arzobispados, Maestrados, Obispados, Priorados, Abadias e Benefic os supplicaremos comunmente a voluntad suya della, segun mejor parecerá cumplir al servicio de Dios e bien de las iglesias e salud de las de todos y honor de los dichos reynos, e los que serán postulados para ello serán letrados. (Clemencín, 1821, p. 579).

Era una exigencia inexcusable que los obispos, como los pastores de almas, tuvieran la ciencia de la doctrina cristiana necesaria para la instrucción del pueblo y la predicación. Debían poseer, pues, una formación competente en teología y moral. A eso se referían los reyes en sus Capitulaciones matrimoniales cuando se imponían mutuamente que "los que serán postulados [para las mitras] serán letrados", como acabamos de ver. A eso mismo aludía Hernando del Pulgar al referirse al gusto de la reina en lo referente a la personalidad de los obispos: "grandes letrados e de vida honesta" eran los preferidos por Isabel.

Ahora bien, personas de esta índole, rectos y doctos, no se hallaban por lo general sino entre los que habían cursado estudios y obtenido grados en alguna Universidad, es decir, entre la burguesía o clase media. Desde luego, candidatos así, instruidos en la ciencia y honestidad de costumbres, no se encontraban entre los magnates y miembros de la alta nobleza, en cuya educación se inculcaban los valores propios de la vida cortesana, caballeresca y guerrera. Por 
eso, en la elección de obispos los reyes rehuían a personas de alto linaje y se decantaban por candidatos de proveniencia más modesta. También de esta opinión era el arzobispo de Toledo, Pedro González de Mendoza, cuando aconsejó a los reyes que en su sucesión se otorgase la sede arzobispal de Toledo a uno de la clase media, sugiriéndoles el nombre del franciscano Cisneros (cf. García Villoslada, 1987, p. 610).

En Cisneros se unían, pues, las virtudes necesarias del (futuro) obispo reformador afín al plan de reforma político-eclesiástica de la propia monarquía y del fundador de una Academia para la instrucción de los clérigos y la renovación del estamento clerical.

\section{Gonzalo Jiménez de Cisneros: apuntes biográficos}

Cisneros nació en Torrelaguna en 1436. Adquirió el grado de bachiller en Derecho canónico y civil en la Universidad de Salamanca, tras cursar estudios de Artes (es decir, Filosofía) y probablemente Teología. Fue ordenado sacerdote en Roma. De regreso en España, tras la muerte de su padre, apremiado por las necesidades de su madre y hermanos, ganó el arciprestazgo de Uceda por bula del Papa Paulo II en 1471. Pero el entonces arzobispo de Toledo, Alfonso (o Alonso) Carrillo de Acuña (1410-1482) se negó a otorgárselo:

\footnotetext{
Firme en su derecho, aquel oscuro clérigo declaró que estaba resuelto a morir antes que ceder a la arbitrariedad del arzobispo. Este, lleno de cólera, lo mandó prender, encerrándolo en la fortaleza de Uceda y luego en el castillo de Santorcaz. En la lobreguez de aquel presidio pasó varios años, que aprovechó para estudiar la Sagrada Escritura y para reflexionar y hacer oración. (García Villoslada, 1987, p. 618).
}

Al salir de prisión el arzobispo Carrillo cambió de opinión y le concedió el arciprestazgo de Uceda. Pero para entonces Cisneros estaba decidido a cambiar de diócesis, lo que, en efecto, hizo permutando en 1474 (el mismo año en que comenzaba el reinado de los Reyes Católicos) dicho arciprestazgo por la capellanía mayor del Cabildo de Canónigos de Sigüenza. El obispo de Sigüenza era, a la sazón, don Pedro González de Mendoza, que supo apreciar las dotes del nuevo canónigo.

En Sigüenza estudió hebreo y arameo junto a un rabino. Sin que sepamos exactamente por qué -Villoslada supone que movido a ello tras las largas meditaciones en su injusto encierro de Uceda y Santorcaz-, tomó luego Cisneros la determinación de abandonar la vida de clérigo secular y abrazar la vida religiosa en la Orden de San Francisco. Aunque el dato no está suficientemente contrastado por los historiadores, se dice que ingresó en el monasterio toledano de San Juan de los Reyes, construido entre 1477-1495 por los Reyes Católicos en acción de gracias por la batalla de Toro (1476) frente al rey de Portugal, que fue entregado a los 
franciscanos de la observancia. Allí ingresó en 1484 como novicio aquel sacerdote y canónigo de 48 años

alto de talla, austero semblante, ojos negros, mirada profunda, nariz aguileña y labios apretados; hombre de pocas palabras, de carácter llano y sencillo, pero un poco áspero, inflexible, enérgico, emprendedor, serenamente intrépido y con el alma llena de altos ideales. Su nombre de Gonzalo lo cambió al hacer la profesión religiosa por el de Francisco, en devoto recuerdo de su santo padre el de Asís. (García Villoslada, 1987, p.618).

Pasó posteriormente al convento de Escalaceli en La Salceda (Guadalajara), donde pronto fue elegido superior (o guardián, según el nombre habitual entre los franciscanos):

Diríase que Fr. Francisco Jiménez de Cisneros, feliz en aquel desierto con sus humildes frailes, estaba llamado a ser, a lo más [...] un santo reformador de tipo casi anacorético. Pero grandes y resonantes sucesos ocurrían entonces en España. El 2 de enero de 1492 Granada caía en manos de los Reyes Católicos. Nombrado arzobispo de la nueva diócesis fray Hernando de Talavera, quedaba la reina Isabel sin confesor. Consultó al cardenal Mendoza, quien le encomendó encarecidamente al guardián de La Salceda. Le llamó entonces la reina a Valladolid, pidiéndole que se encargase de dirigir su conciencia y, tras una resistencia inútil, aceptó fray Francisco el cargo de confesor. (García Villoslada, 1987, p. 618).

Viendo los franciscanos encumbrado e influyente al guardián de La Salceda, pronto lo eligieron provincial de Castilla en 1494. Cisneros aceptó con presteza, porque deseaba introducir la reforma de la Observancia en todos los conventos franciscanos. De otro lado, desde hacía tiempo los reyes deseaban llevar a cabo la reforma monástica en toda España. La habían solicitado a Inocencio VIII en 1491, aunque se les había rehusado el permiso. Pero en 1493, ya con Alejandro VI en el solio pontificio, habían obtenido las facultades necesarias por medio de un Breve, en el que se les autorizaba para la elección de una persona idónea que visitara y reformara todos los conventos y monasterios femeninos de toda España. En una posterior Bula pontifici se ampliaban las facultades de supervisión y visita, que se extendían a la inspección y reforma de todas las casas religiosas en España, de cualquier orden y sexo. Así, con plenos poderes de Roma, con la designación de los Reyes Católicos y con el poder que el nombramiento como arzobispo de Toledo (sede primada de España) le otorgó a partir de 1495, emprendió Cisneros la ardua labor de la reforma de la vida religiosa en España. Es verdad que esta reforma estaba ya en marcha desde hacía tiempo entre diversas órdenes monásticas y religiosas, particularmente entre benedictinos, cistercienses, agustinos y dominicos. Sin embargo, entre los franciscanos, donde había comenzado con energía, pronto había quedado detenida, por causa del escaso número aún de los observantes (o reformados) y de las persecuciones contra ellos de los conventuales o claustrales (cf. García Villoslada, 1987, p. 620). 
Con su habitual decisión puso Cisneros manos a la obra de la reforma de los religiosos, comenzando precisamente por los franciscanos. Aunque poseía autorización pontificia y real para emprender la reforma de todas las órdenes religiosas del reino, no parece que actuara directamente más que en su propia Orden. Obraba prudentemente, ya que, en las demás órdenes, que trabajaban espontáneamente en su propia reforma, mal se habría llevado la intromisión de un fraile extraño.

García Villoslada hace una observación final que nos parece de relevancia suficiente para traerla a colación aquí. A la vista de la reforma cisneriana de los franciscanos se constata de un lado que los frailes de la observancia se inclinaban a la vida de recogimiento, más aún, a la vida eremítica. Se ha observado por no pocos historiadores que el fenómeno de los alumbrados estuvo siempre vinculado a los conventos de San Francisco. Pero, de otro lado, precisamente de estos conventos reformados salen los misioneros más ardientes para el Nuevo Mundo, comenzando por los llamados doce apóstoles de México. ¿Es esto hecho ilógico? Así lo cree García Villoslada, que ve en ello la paradoja del alma del propio Cisneros:

\footnotetext{
Espíritu de recogimiento y de apostolado, contemplación y acción, ilusiones de profetismo apocalíptico y visión realista de la vida. Estas y parecidas antinomias, ¿no latían en el alma misma de Cisneros, fraile de oración y penitencia, gobernante y político de admirable sentido práctico, y -no ocultemos esta faceta- hombre crédulo fascinado por lo que presentaba algún aspecto de sobrenatural y protector de beatas y de visionarios?. (García Villoslada, 1987, p. 622).
}

Pero sin duda el aspecto más importante de la reforma emprendida por Cisneros fue la fundación de la Universidad de Alcalá de Henares.

\section{La Universidad de Alcalá entre reforma eclesiástica y humanismo: la disputa académica}

Como se acaba de decir, la fundación de la Universidad de Alcalá es uno de los capítulos más relevantes, si no el que más, del programa de reformas ideado por el cardenal Cisneros. En efecto, la Universidad de Alcalá fue un instrumento fundamental para la reforma del clero hispánico. La futura Universidad debía ser la Academia donde pastores de almas y teólogos, especialmente ilustrados en la Biblia y la moral, recibieran la necesaria formación teológica que después difundieran entre el pueblo cristiano por medio de "la predicación de las santas Escrituras, que es el fin principal de la Teología" (Cisneros, 1510, cap. 46).

Sobre el propósito de Cisneros en la fundación de la Universidad de Alcalá hay dos tesis fundamentales en contienda. Según la primera, la Universidad de Alcalá fue ante todo y únicamente una institución académica dedicada a la formación del clero como medio de reforma 
eclesiástica. La segunda tesis, por su parte, sostiene que, siendo ello cierto, no es obstáculo en absoluto para reconocer que, junto a la instrucción eclesiástica, el espíritu humanístico inspiró este proyecto. De la primera tesis el principal defensor fue Marcel Bataillon. De la segunda, el jesuita Ricardo García Villoslada.

Dice en efecto este autor:

Se ha repetido muchas veces que aquella Universidad fue el más rico florón del humanismo español; y se ha reaccionado contra esta idea, acentuando, en cambio, su carácter esencialmente clerical y teológico. No hay pugna entre ambos conceptos, porque el humanismo español, más que el de otras naciones, se mostró siempre solidario de la tradición eclesiástica y, por otra parte, la teología española se reformó en la primera mitad del siglo XVI precisamente en virtud de los fermentos humanísticos que se le inyectaron. (García Villoslada, 1987, p. 628).

Salía así el jesuita al paso de la idea manifestada por Bataillon al inicio de su monumental obra Erasmo y España, donde se afirmaba que la fundación de la Universidad de Alcalá era meramente un proyecto eclesiástico ideado para mejorar la calidad y la formación del clero español. Afirmaba en tal sentido Bataillon:

Nada nos autoriza a creer que Cisneros haya considerado la gran masa de los sacerdotes y religiosos como un posible peligro. Pero fue en él preocupación constante el mejorar su calidad. Todos sus esfuerzos de reforma son un testimonio de ello, y mucho más elocuentes aún son las fundaciones con las cuales quiso resolver el problema del reclutamiento, de la selección. La creación de la Universidad de Alcalá no fue sino la erección de un organismo completo de enseñanza eclesiástica: elemental, media y superior. Hace mucho que se ha señalado este carácter esencialmente clerical y práctico en un artículo que pasó inadvertido casi por completo. Después, Federico de Onís ha vuelto con fuerza sobre el asunto, subrayando la diferencia fundamental que separa dos instituciones casi contemporáneas, como son la Universidad de Alcalá y el Collége de France. Pero todavía es tan frecuente el error de considerar la fundación de Cisneros como un triunfo del humanismo, que es casi imposible precisar sus relaciones con la obra de restauración eclesiástica y con el renacimiento de la antigüedad cristiana. (Bataillon, 1950, p. 10).

Nos parece que el juicio del estudioso francés adolece de cierta parcialidad de apreciación. Todo indica que en la fundación de la Universidad de Alcalá se dieron conjuntamente humanismo y reforma eclesiástica, aunque Bataillon los considere excluyentes. La presencia de este elemento humanístico salta a la vista en las Constituciones que dan vida a la Universidad. En ellas abundan las ideas e instituciones de naturaleza humanística, sobre todo en materia 
filológica y especialmente en lo relativo al dominio del latín y a su uso elegante, tanto en discursos académicos como en sermones eclesiásticos, del que debían dar muestras de capacidad los que obtuvieran la licentiadocendi. Por eso, la posición de García Villoslada a este respecto nos parece más circunspecta y atenta a los datos. Permítasenos una nueva cita del historiador jesuita. Dice así:

El nacimiento de Alcalá fue una gran promesa [...] Aquella genial creación típicamente renacentista intentaba promover, para el mayor servicio de la Iglesia, lo literario, filológico y humanístico según los gustos del día; lo filosófic y teológico con amplia libertad de crítica y de tendencias; lo científico y lo espiritual. La Universidad de Alcalá ha sido comparada [por Bataillon] con el Collège de France, fundado en 1530 por Francisco I a ruegos de Guillermo Budé [...] Sus divergencias son demasiado palmarias para insistir en ellas. Sería mucho más acertado compararla con la Universidad de Wittenberg, fundada en 1502 por el duque Francisco de Sajonia, con profesores como Juan Staupitz, Martín Lutero y Felipe Melanchton. Lo que Wittenberg para la Reforma protestante, eso significa Alcalá para la Contrarreforma católica. De Wittenberg puede decirse que sale la traducción luterana de la Biblia; de Alcalá, la Políglotacomplutense. (García Villoslada, 1987, p. 628).

\section{La tesis de Bataillon sobre el pretendido escotismo de la Universidad cisneriana}

Pero la cuestión fundamental que este trabajo pretender clarific $r$ es la tesis de una hipotética orientación escotista de la Universidad de Alcalá, como ha sugerido Bataillon.

En dos ocasiones, al menos, se expresa este autor al respecto en su obra Erasmo y España. En efecto, ya en las primeras páginas afirma el estudioso francés:

Desde su promoción al arzobispado de Toledo, Cisneros había concebido el proyecto de renovar la enseñanza teológica española por la introducción del escotismo. Quizás el ejemplo de los dominicos, que encendieron una nueva hoguera de tomismo en San Gregorio de Valladolid, no haya sido extraño a esta determinación. Pero en esos días España está vuelta hacia París. En la Sorbona es donde un joven dominico español, Vitoria, va a respirar la atmósfera de un renacimiento tomista que, sin embargo, aparece mucho más vivamente en Italia, con Cayetano. Un tal fray Pedro lleva a París la noticia de los proyectos de Cisneros. El humanista Robert Gaguin se dirige al punto a Étienne Brulefer, fraile minorita, retirado por entonces en Maguncia, como al doctor más digno de enseñar en España la sutil teología de Escoto. Gaguin, que ya ha viajado al otro lado de los Pirineos, pondera al franciscano la fecundidad 
de la tierra, la religión de los españoles y las atenciones que tienen para con los extranjeros de mérito [...] [Allí] podrá encontrar un ambiente favorable, tanto mejor dispuesto a recibir la doctrina de Duns Escoto cuanto que a su vez el nuevo arzobispo es franciscano. (Bataillon, 1950, p. 10-11).

Más adelante vuelve a insistir de nuevo en esta idea:

Si la Universidad de Alcalá aparecía como innovadora en España, era sobre todo por su Facultad de Teología. En este campo Salamanca había permanecido fie a la escolástica fundamental, a Santo Tomás y al Maestro de las Sentencias. Cisneros, como se ha visto, se empeñaba en introducir en España la filosofía de Duns Escoto, que, en los países del Norte, compartía con el tomismo la dignidad de doctrina clásica. El gran pensador franciscano quedó colocado en Alcalá en pie de igualdad perfecta con Santo Tomás. (Bataillon, 1950, p. 16).

Ésta es, pues, la cuestión a analizar: si en verdad en Alcalá se pretendió por parte de Cisneros establecer un centro de inspiración escotista, como sostiene Bataillon. De modo preliminar hay que decir que entre los estudiosos hay al respecto más pareceres en contra que a favor. Desde luego de lo que se trata no es tanto de contar el número de partidarios o detractores, sino de ponderar y valorar la calidad de las razones.

Una primera crítica a Bataillon vino del dominico Beltrán de Heredia, quien a propósito de los motivos de Cisneros en el proyecto de fundación de la Universidad de Alcalá afir ó hace ya tiempo:

Con abundar los trabajos de investigación acerca de los comienzos [de la Universidad de Alcalá], no se han puesto todavía en claro ciertos extremos que interesan para conocer con precisión la idea del gran cardenal de España. Marcel Bataillon, escritor familiarizado con el espíritu de la época y hábil en descubrir a través del documento el curso de los hechos, y aún el móvil que actúa sobre las personas, atribuye a Cisneros "el proyecto de renovar la enseñanza de la teología española por la introducción del escotismo". Y tal vez, añade, el ejemplo dominicano, que acababa de cristalizar en la espléndida fundación de San Gregorio, de Valladolid, no fue extraño a esta idea. El acierto, que tantas veces ha acompañado al insigne profesor de la Sorbona en sus apreciaciones de las cosas de España, falla con toda evidencia en este caso. El ilustre prelado toledano era demasiado comprensivo para proponerse una obra de horizontes tan amplios como la restauración de la Teología española, a base de Escoto. A falta de otra prueba, basta leer la constitución fundamental relativa a la enseñanza de la Teología en Alcalá para convencerse de ello. Escoto comparte allí, con Santo Tomás y los nominales, las cátedras de la facultad, sin sombra alguna de superioridad, puesto que viene en segundo lugar. [...] La idea básica del gran promotor de los estudios sagrados fue dotar a España de 
una Universidad eminentemente teológica; pero no de aquella Teología rancia de tiempos anteriores, y que aún perduraba en algunos espíritus retardatarios, sino de un centro modernísimo, que en la especulación escolástica se diese la mano con la erudición y el buen gusto humanístico que iba conquistando todos los puestos. (Beltrán de Heredia, 1973, p. 443. Cursivas propias).

Tampoco parecen dar la razón a Bataillon las palabras de Fr. José Ximénez Samaniego, de la Orden de San Francisco, autor de una de las pocas biografías españolas de Escoto. En su Vida del Venerable P. Juan Dunsio Escoto, publicada en Madrid a mitad del siglo XVIII (obra en la que el tono hagiográfico y de exaltación de Escoto es constante) se dice, sin embargo, escuetamente, de Alcalá y Cisneros: "En la Universidad de Alcalá el santo arzobispo y cardenal de España. D. Fr. Francisco Ximénez de Cisneros, su fundador magnífico, dio a Escoto la cátedra de prima con aprobación del papa Julio II" (Ximénez Samaniego, 1741, p. 269-270). Ninguna referencia al escotismo de la Universidad de Alcalá ni a preeminencia alguna del filósofo franciscano sobre los demás maestros recomendados en dicha Universidad. Únicamente se constata la creación de una cátedra de teología apud Scotum.

Un historiador actual de la Universidad de Alcalá, Luis Miguel Gutiérrez Torrecilla, dice de la introducción de la triple vía teológica (con la que se había introducido la cátedra de Escoto) que era "un revulsivo para revitalizar un estudio que ya en aquella época tendía a ser repetitivo y escasamente creativo" (Gutiérrez Torrecilla, 1994, p. 26). En modo alguno se percibe un deseo de promoción, ni tanto menos de preeminencia, del escotismo. De hecho, según Gutiérrez Torrecilla, las líneas fundamentales de pensamiento y de acción de la Universidad de Alcalá fueron lejanas al escotismo desde el principio. Así, mientras que en el siglo XVI los aspectos más sobresalientes de la Facultad de Teología de Alcalá fueron la significativa presencia de sus teólogos en el Concilio de Trento, la elaboración de dictámenes y consejos para el rey en cuestiones de Estado y un apoyo claro a las ideas erasmistas, en el siglo XVII los autores que marcan la doctrina filosófico-te ógica predominante en Alcalá serán el dominico Melchor Cano y el jesuita Súarez (cf. Gutiérrez Torrecilla, 1994, p. 26-27).

La única fuente concorde, al menos en parte, con Bataillon sobre el carácter predominantemente escotista de la Universidad de Alcalá parece ser únicamente Lucas Wadding (1588-1657), erudito franciscano del siglo XVII y, sobre todo, editor de una primera colección de la Opera omnia de Escoto. En la Vida del autor (contenida precisamente en el primer volumen de esta edición) Wadding afirmaba que de entre todas las Academias donde se había instituido una cátedra de Escoto la Universidad de Alcalá (Complutense) había dado a la doctrina del Doctor Sutil el primer puesto (In Complutensi ómnium primariam Scotus obtinuit). Decía en concreto:

El gran provecho de esta sagrada doctrina [de Escoto] fue comprendida por los doctores de la Iglesia y los prefectos de las letras [...] Entré en contacto con las tres Universidades más nobles de España: Coimbra, Salamanca y Alcalá. En 
cada una de ellas supe que se habían instituido cátedras y destinado maestros para la enseñanza de la doctrina de Escoto. (Wadding, 1639, p. 25).

Y -prosigue Wadding- si en Coimbra y Salamanca la retribución económica y el prestigio de la cátedra de Escoto llegó a ser importante, "en la Complutense [la doctrina de] Escoto obtuvo la primera [posición] de todas [las Universidades hispánicas]” (Wadding, 1639, p. 25)1.

De hecho, ni siquiera hay que descartar la posibilidad de que con el adjetivo primariam Wadding se refiera al hecho de que entre las tres Universidades hispánicas la cátedra de Escoto se implantara por primera vez (primariam) en Alcalá, como de hecho ocurrió. Incluso el uso del adjetivo primariam podría haber querido expresar la idea de que la cátedra apud Scotum era matutina (cátedra de prima), como era usual decir entonces, es decir, la cátedra que impartía sus lecciones por la mañana. En resumen, no es claro el sentido de la expresión empleada por Wadding en relación con el carácter de primera o primaria que la cátedra de Escoto obtuvo entre las tres Universidades hispánicas. Si ello es así, la pretensión de Bataillon resulta más débil aún.

En realidad, lo que ocurre en la Universidad de Alcalá es que las Constituciones de la misma en su capítulo 43 (sobre las Cátedras de Teología y su tiempo de duración [De cathedris

1/ Wadding, L. (1639). Authoris vita, a R. P. Fr. Luca Waddingo conscripta. En: R. P. F. loannis Duns Scoti, doctoris subtilis ordinis Minorum Opera omnia, quae hucusque reperiri potuerunt (pp. 25-26). Ludguni: Sumptibus Laurentii Durand: "Magnum hoc sacrae doctrinae emolumentum esse perceperunt Ecclesiae Doctores, et rei litterarie praefecti. Nam tantum abest, ut has sopire lites, aut contentions extinguere voluerint, ut propositis potius praemiis fovere, institutis stipendiis, erectis contrariorum dogmatum cathedris, solerter excogitaverint. Peculiares habet Professores, et sectatores in Academiis Doctor Angelicus, suos habet et Doctor subtili. Ex peculiari docetur cathedra D.Thomae, ex altera Scoti doctrina. Ad tres nobilissimas in Hispania accessi Universitates, Conimbricensem, Salmanticensem, Complutensem; in unaquaeque harum, vidi instituta subsellia, et destinatos Magistros pro Scoti disciplina tradenda. In Parisiensi item Academia, in Patavina, Ticinensi, immo et in ipsa Urbe, orbis capite, peculiares cathedras Scotus obtinuit. Eo etiam habetur in pretio, ut dignitate, stipendio, aut hora commoditate multis in locis non cedat eius cachedra illi, quae S. Thomae retinet nomen. In Conimbricensi etenim Academia aequalis sunt stipendii et auctoritatis. In Salmaticensi haud minoris emolumenti, quae Scoti est; et magno conatu ad illam adspirant doctissimi illius Academiae Magistri. In Complutensi omnium primariam Scotus obtinuit. Ultra haec stricte cavit Universitas Salmancicensis, ne Scoti cathedrae Professor aliam, quam Scoti, discipulis tradat doctrinam, neque eam summatim, aut per conclusiones duntaxat comprehendat, sed clare mentem eius et textum largius exponat. | Perceperunt utique optimi illi Magistri et cathedrarum institutores, magnum studiosorum profectum ex scholastica hac concertatione et quotidiana dissertatione provenire, quorum alias ingenia torpescerent et hebesceret intellectus, si communibus duntaxat principiis, quasi statutis scholasticae disciplinae metis, caeca quadam manuductione devoverentur. Ferrum ferro exacuitur e homo exacuit faciem amici sui, conserendo, disserendo, penitius examinando. Si plura obiiciatur et sententiae retundantur, uti ferrum ferro consticatum, aciem concipit [26], ita ex adverso docentis ingenium exercetur, excitatur, acuitur. Expedit itaque contrarias in studiis Ecclesiasticis esse opiniones ad exercendum ingenium et excutiendam studentium pigritiam". (Las cursivas son mías). 
Theologiae et tempore quo durabitearum regentia]) establecían una nueva normativa sobre diversas vías teológicas que la Universidad permitía seguir oficialmente. En efecto, en el capítulo 43 se establecía la creación "en la Facultad de Teología de tres cátedras magistrales según las tres vías frecuentadas en estos tiempos en las Escuelas, a saber, del santo Doctor, de Escoto y de los Nominales" (in Theologica facultate tres cathedrae magistrales iuxta illas tres vias in scholis his temporibus frequentatas, videlicet Doctoris Sancti, et Scoti, et Nominalium). No parece que de este texto se pueda deducir la pretensión de Cisneros de hacer de la Universidad de Alcalá el bastión del escotismo en España, como opina Bataillon. Que la filosofía de Escoto adquiere en Alcalá la dignidad de vía teológica sustentada en una cátedra magistral de Teología es claro. En realidad con ello las Constitutiones, como en tantas otras ocasiones, no hacen más que seguir el modo parisiense (more parisiensi), el estilo sorbónico (en efecto, en París ya existían cátedras teológicas de Tomistas, Escotistas y Nominales), dando a su vez carácter de norma a lo que ya era un uso extendido en muchas universidades del centro de Europa ("tres cátedras magistrales, tantas como vías seguidas en las escuelas en estos tiempos, a saber, del santo Doctor, de Escoto y de los Nominales").

Sin embargo, con estas palabras del capítulo 43 de las Constitutiones de la Universidad no se expresa preferencia alguna por Escoto. Si hubiera de admitirse alguna preferencia habría que decir que se decanta más bien por Tomás de Aquino. En efecto, hay un par de aspectos inequívocos que manifiestan la excelencia de la vía de santo Tomás según las Constituciones cisnerianas. Aparece citada en primer lugar. Y el orden de los nombres o autores en estas citas adhonorem siempre es importante. Además, Tomás de Aquino, en lugar de ser citado por su nombre, aparece mencionado honoríficamente como el Santo Doctor. A propósito de estos adjetivos, hay que decir que si Tomás ya había sido declarado santo (en 1323), no lo había sido aún como Doctor Ecclesiae, lo que será obra de Pío V (un Papa dominico) en 1567, cuatro años después de la conclusión de Trento. Sin embargo, el uso de la expresión de Santo Doctor del capítulo 43 de las Constitutiones da a entender que la consideración de Tomás como doctor de la Iglesia, aún previa a la declaración pontificia en 1567, era admitida a comienzos del siglo XVI. Así pues, en las Constitutiones de la Universidad de Alcalá (1510), encontramos un cierto reconocimiento anticipado en 57 años de su calidad (no ciertamente de su condición canónica) de Doctor Ecclesiae.

En definitiva, la interpretación de Bataillon del capítulo 43 de las Constitutiones en el sentido de considerar que en él se hace presente el deseo de Cisneros de imponer el escotismo en Alcalá nos parece exagerada y sin respaldo suficiente. Más modestamente parece que se trata, como hemos sugerido antes, de la confirmación jurídico-académica de un uso ya extendido en la Sorbona de París, a la que la Universidad de Alcalá estaba tan unida, de cultivar la Teología según diversos caminos o vías posibles. Con esta amplitud de miras, Cisneros daba muestras de hacer suyo el espíritu erasmiano de concordia y tolerancia, al que el propio capítulo 43 de las Constituciones apela como motivo de fondo del establecimiento de las tres vías teológicas. 


\section{Bibliografía}

BATAILLON, M. (1950). Erasmo y España. Estudios sobre la historia espiritual del siglo XVI. México: FCE. BELTRÁN DE HEREDIA, V. (1973). Miscelánea Beltrán de Heredia, vol. IV. Salamanca:Editorial OPE.

CISNEROS, F. (cardenal) Jiménez de. (1716). Constitutiones Insignis Collegij Sancti Ildephonsi, ac perinde totius almae Complutensis Academiae, ab illustrissimo ac reverendissimo Fr. Francisco Ximenio, Cardinali Sancta Balbinae et Archieopiscopo Toletano, eiusdem Collegii et Academiae único fundatore, olim sancitae. Compluti: Ex Officina Iuliani Garcia Briones, Typographym Universitatis. Las Constituciones originales son de 1510.

CLEMENCÍN, D. (1821). Capitulaciones del matrimonio entre la Princesa doña Isabel y D. Fernando, rei de Sicilia, ajustadas en Cervera, a 7 de enero de 1469. En: D. Clemencín, Diego. Elogio de la Reina católica doña Isabel, al que siguen varias ilustraciones sobre su reinado (pp. 577-581). Madrid: Imprenta de I. Sancha.

DEL PULGAR, H. (1780). Crónicas de los Reyes Católicos don Fernando y doña Isabel de Castilla y de Aragón. Valencia. Imprenta de Benito de Monfort.

FITA COLOMÉ, F. (1893). Concilios españoles inéditos: provincial de Braga en 1261 y nacional en Sevilla en 1478. Boletín de la Real Academia de la Historia, 22 (pp. 209-257).

GALÍNDEZ DE CARVAJAL, L. (1787). Anales breves del reinado de los Reyes Católicos don Fernando y doña Isabel [...] que dexó manuscritos el Doctor D. Lorenzo Galíndez Carvajal. Por D. R.Floranes Robles y Encinas. (Ms. Biblioteca Nacional 11.174). Por mayor comodidad hemos consultado esta obra en la excelente recopilación de Rodríguez Valencia, V. (1970). Isabel la Católica en la opinión de españoles y extranjeros. Siglos XV al XX. Tomo I: siglos XV al XVI. Valladolid: Instituto Isabel la Católica de Historia eclesiástica.

GARCÍA VILLOSLADA, R. (1987). Historia de la Iglesia Católica, vol. III (Edad Nueva). Madrid: BAC. WADDING, L. (1639). Authoris vita, a R. P. Fr. Luca Waddingo conscripta. En: R. P. F. Ioannis Duns Scoti, doctoris subtilis ordinis Minorum Opera omnia, quae hucusque reperiri potuerunt. Vol. I. Ludguni: Sumptibus Laurentii Durand.

XIMÉNEZ SAMANIEGO (OFM), J. (1741). Vida del Venerable P. Juan Dunsio Escoto, doctor mariano y subtil, príncipe y universal maestro de la Escuela Franciscana. Madrid: Bernardo de Villadiego. 